\title{
Effects of oral administration of Garcinia dulcis flower extract on arterial blood pressure and renal excretory functions in rats
}

\author{
Nattaya Thongsepee ${ }^{a, b, *}$, Umarat Srisawat $^{\mathrm{a}}$, Wilawan Mahabussarakam ${ }^{\mathrm{c}}$, \\ Sophapun Ekarattanawong ${ }^{\mathrm{a}}$, Noppadon Suttirak ${ }^{\mathrm{d}}$, Siriphun Hiranyachattada ${ }^{\mathrm{e}}$ \\ a Department of Preclinical Science, Faculty of Medicine, Thammasat University, Pathum Thani 12120 \\ Thailand \\ b Thammasat University Research Unit in Nutraceuticals and Food Safety, Faculty of Medicine, \\ Thammasat University, Pathum Thani 12120 Thailand \\ c Division of Bioscience, Faculty of Science, Prince of Songkla University, Hat Yai, Songkhla 90112 \\ Thailand \\ d Laboratory Animal Center, Thammasat University, Pathum Thani 12120 Thailand \\ e School of Pharmacy, Walailak University, Nakhon Si Thammarat 80160 Thailand
}

*Corresponding author, e-mail: nattayat@tu.ac.th

\begin{abstract}
Intravenous infusion of either camboginol or morelloflavone from Garcinia dulcis (GD) exerted diuretic, hypotensive, and vasorelaxant effects in either normotensive or hypertensive rats. This study aims to investigate the effects of GD flower extract on arterial blood pressure (ABP) and renal excretory functions. Male Wistar rats (8-weekold) were divided into 4 groups (group I-IV, $n=6$ each) in both acute and sub-chronic protocols. The GD extract was orally administrated to group II-IV at the dose of 50,100, or $200 \mathrm{mg} / \mathrm{kg}$, respectively, while group I served as vehicle control. The oral administration was performed before the experiment in acute protocol and daily for 2 weeks in the sub-chronic protocol. The ABP and renal excretory functions were measured in the anesthetized rats. The levels of fasting blood glucose (FBG), plasma lipid profiles, and liver enzymes were evaluated in the sub-chronic experiment along with liver histology. The results showed that acute administration of GD extract significantly decreased ABP but increased renal blood flow, glomerular filtration rate, urine flow rate, osmolar clearance, and negative free water clearance when compared with the control. In the sub-chronic protocol, the GD extract significantly decreased ABP but did not alter the renal excretory functions. The plasma levels of FBG, lipid profiles, liver enzymes, and the histology of liver were not changed. It is concluded that acute oral administration of GD extract possessed hypotensive and diuretic effects whereas the sub-chronic treatment of GD showed hypotensive effect and no alterations in liver function, FBG, and plasma lipid profiles.
\end{abstract}

KEYWORDS: Garcinia dulcis, camboginol, morelloflavone, diuretic effect, hypotensive effect

\section{INTRODUCTION}

Hypertension is a chronic cardiovascular disease in which the arterial blood pressure (ABP) is elevated leading to an increase in the risks of heart, brain, kidney, and other diseases and promotes premature death. In 2019, the World Health Organization estimated 1.13 billion people worldwide have hypertension. The pathophysiological mechanisms associated with hypertension are generally understood. One of the possible causes of hypertension is an overproduction of free radicals that damage cardiovascular and renal systems in which characterized by an overactivity of the sympathetic nervous system [1] and renin-angiotensin-aldosterone system (RAAS) [2], the inability of kidneys to excrete sodium [3], and the endothelial dysfunction [4], resulting in increased vascular resistance and fluid overload and finally raised ABP. Recently, a large number of local plants with antihypertensive therapeutic potential have been studied because of their various bioactivities [5], more safety and efficacy, cost-effectiveness, and fewer side effects. However, more scientific researches are needed to verify the effectiveness and elucidate the safety profile of such herbal remedies for their antihypertensive potential.

The tropical plant Garcinia dulcis (GD) Kurz, 
local Thai name Ma-Phud, belongs to the Guttiferae family and grows mainly in the Southeast Asia region. Various parts of this plant have been used as medicine; leaves and seeds were used for lymphatitis, parotitis, and struma treatment; stem bark was used as an antiseptic agent; fruit juice was used for anti-scurvy and expectorant for the relief of cough and sore throat; and its root extract was used as an antipyretic and antitoxin agent [6-9]. The extracted substances from GD contained at least 4 groups of phenolic compounds including flavonoids, benzophenone, xanthones, and benzophenone-xanthone dimer [6-9]. The yield of chemical constituents extracted from GD depended on the part of the plant specimens and the procedure of purification. Its phenolic compounds which have been shown to possess antibacterial and antioxidative activity including cambogin, camboginol, dulcisflavone, epicatechin, and morelloflavone from fruits [6], dulcisxanthone C-F and dulcinone from flowers [7], and dulcisxanthone $\mathrm{G}$ from seeds [8]. Our previous studies found that the intravenous administration of either camboginol or morelloflavone extracted from the fruits of GD exerted diuretic and hypotensive effects in either anesthetized normotensive or hypertensive rats. An experiment in isolated thoracic aorta revealed the vasorelaxant action of camboginol and morelloflavone in both normotensive and hypertensive rats, and their mechanism of action involved an endothelial nitric oxide (NO)-dependent pathway [10-13].

This study aims to evaluate the effects of acute and sub-chronic oral administration of the GD flower extract on cardiovascular parameters including arterial blood pressure (ABP) and renal excretory functions comprising renal vascular resistance (RVR), clearance of para-amino hippuric acid $\left(\mathrm{C}_{\mathrm{PAH}}\right)$ and inulin $\left(\mathrm{C}_{\text {In }}\right)$ as markers of effective renal plasma flow (ERPF) and glomerular filtration rate (GFR), respectively, urine flow rate $(\dot{V})$, osmolar clearance $\left(\mathrm{C}_{\mathrm{Osm}}\right)$, negative free water clearance $\left(\mathrm{TC}_{\mathrm{H}_{2} \mathrm{O}}\right)$, plasma osmolarity $\left(\mathrm{P}_{\mathrm{Osm}}\right)$, and urine osmolarity $\left(\mathrm{U}_{\mathrm{Osm}}\right)$ in anesthetized rats. The effects of GD flower extract on the levels of fasting blood glucose (FBG), plasma lipid profiles, liver enzymes, and histology of liver were also evaluated in the sub-chronic protocol to assess its toxicity.

\section{MATERIALS AND METHODS}

\section{Preparation of Garcinia dulcis flower extract}

The flowers of GD were collected from Songkhla province in the southern part of Thailand. The voucher specimen has been deposited at Prince of Songkla University Herbarium (Collection No. 02 and Herbarium No. 0012625), Faculty of Science, Prince of Songkla University, Songkhla, Thailand. The GD flowers (488 g) were extracted at room temperature sequentially with acetone for $72 \mathrm{~h}$. Removal of the solvents from the extract yielded the acetone extract $(85.50 \mathrm{~g})$. This acetone extract was fractionated by dissolving in hexane to give a soluble (13.45 g) and insoluble (70.06 g) fractions. The hexane insoluble fraction was used in this study. To identify the chemical components, $20 \mathrm{mg}$ of the tested fraction was subjected to a silica gel column chromatography and eluted with the $10 \%$ $\mathrm{MeOH}$ in $\mathrm{CH}_{2} \mathrm{Cl}_{2}$. The collected fractions were chromatographed on thin-layer chromatography (TLC) using silica gel as a stationary phase and 10\% $\mathrm{MeOH}$ in $\mathrm{CH}_{2} \mathrm{Cl}_{2}$ as a mobile phase compared with the reference compounds including camboginol and morelloflavone.

The hexane insoluble fraction of the GD flower extract was dissolved in a small amount of dimethyl sulfoxide (0.3\% DMSO; Sigma-Aldrich, Darmstadt, Germany), then further dissolved in corn oil (Mazola, Bangkok, Thailand) for oral gavage at the doses of 0 (corn oil as a vehicle), 50, 100, and $200 \mathrm{mg} / \mathrm{kg}$ body weight (BW). The volume of oral gavage is $2.5 \mathrm{~mL} / \mathrm{kg}$ BW.

\section{Animals and the experimental protocol}

Male Wistar rats (7-week-old, $n=48$ ) were purchased for the Siam Nomura International Co. Ltd. and were transported to the Animal Laboratory Center of Thammasat University. They were housed under standard conditions: room temperature $22 \pm 1{ }^{\circ} \mathrm{C}$, relative humidity $30-70 \% \mathrm{RH}$, light intensity 130-325 Lux, and 12/12 dark-light cycle and were fed with commercial pellet food and a reverse osmosis water ad libitum.

After acclimatization for a week, the rats were randomly divided into 4 groups: I-IV ( $n=6$ each), based on the dose of the GD flower extract administration: 0 (vehicle), 50, 100, and $200 \mathrm{mg} / \mathrm{kg} \mathrm{BW,}$ respectively, in each acute and sub-chronic protocol. The oral administration was performed immediately before the experiment in the acute protocol and daily for 2 weeks in the sub-chronic protocol. The experimental protocols were adhered to $\mathrm{NIH}$ Guiding Principles in the Care and Use of Animals and were approved by the Thammasat University Animal Care and Use Committee under Protocol No. 007/2018. 


\section{Arterial blood pressure (ABP) and renal excretory function study}

A similar protocol of $A B P$ and renal excretory function study was used in both acute and sub-chronic groups. On the day of the experiment, either vehicle or GD flower extract was orally administered to each rat. Immediately, a rat was put in the chamber for induction to be anesthetized with 5\% isoflurane (RWD, Shenzhen, China) supplied with oxygen $4 \mathrm{~L} / \mathrm{min}$ for $1 \mathrm{~min}$, and then the anesthetized rat was removed from the chamber, placed on an electrical temperature control pad, and maintained the anesthetized status with $0.9-2 \%$ isoflurane supplied with oxygen $0.9 \mathrm{~L} / \mathrm{min}$ on face mask throughout the experiment. The right jugular vein was cannulated for infusion of the renal clearance markers containing $1 \%$ PAH (Sigma-Aldrich, Darmstadt, Germany) and $1 \%$ inulin (Sigma-Aldrich, Darmstadt, Germany) in $0.9 \%$ saline solution at the rate of $16 \mathrm{~mL} / \mathrm{min} / \mathrm{kg}$ BW. The left carotid artery was cannulated for blood sampling and continuous $\mathrm{ABP}$ recording using the PowerLab system (model 26T, ADInstruments, New South Wales, Australia). The urinary bladder was cannulated for urine sampling.

After infusion of clearance marker for $30 \mathrm{~min}$, 4 consecutive 30-min urine collections $\left(\mathrm{U}_{1}\right.$ to $\mathrm{U}_{4}$ ) were performed during the $120 \mathrm{~min}$ of the experimental period. Arterial blood samples $(1 \mathrm{ml})$ were taken at the end of $\mathrm{U}_{1}$ and $\mathrm{U}_{3}$ periods and centrifuged at $3000 \mathrm{rpm}$ for $10 \mathrm{~min}$ for plasma collection. The plasma and urine samples were kept at $-20^{\circ} \mathrm{C}$ until analysis of the $\mathrm{PAH}$ and the inulin levels using spectrophotometry $[14,15]$. The $\dot{V}$ was determined gravimetrically by collecting urine into pre-weighed tubes and assuming a density of $1 \mathrm{~g} / \mathrm{ml}$. $\quad \mathrm{P}_{\mathrm{Osm}}$ and $\mathrm{U}_{\mathrm{Osm}}$ were measured by using Micro-Osmometer (model Osmomat 030D, Gonotec, Berlin, Germany).

The $\mathrm{C}_{\mathrm{PAH}}, \mathrm{C}_{\mathrm{In}}$, and $\mathrm{C}_{\mathrm{Osm}}$ were calculated according to the clearance equation; $\mathrm{C}_{\mathrm{X}}=\left(\dot{\mathrm{V}} \times \mathrm{U}_{\mathrm{X}}\right) / \mathrm{P}_{\mathrm{X}}$, when $\dot{V}$ is the urine flow rate, $U_{X}$ is urine concentration of $\mathrm{X}, \mathrm{P}_{\mathrm{X}}$ is the plasma concentration of $\mathrm{X}$, and $\mathrm{X}$ is either of $\mathrm{PAH}$, inulin, or osmolality. $\mathrm{TC}_{\mathrm{H}_{2} \mathrm{O}}$ was calculated using equation $\mathrm{TC}_{\mathrm{H}_{2} \mathrm{O}}=\mathrm{C}_{\mathrm{Osm}}-\dot{\mathrm{V}}$. The $\mathrm{C}_{\mathrm{PAH}}$ and $\mathrm{C}_{\text {In }}$ were taken as the indices of ERPF and GFR, respectively. The $\mathrm{C}_{\mathrm{Osm}}$ and $\mathrm{TC}_{\mathrm{H}_{2} \mathrm{O}}$ were the indices of urinary electrolyte excretion and free water reabsorption, respectively. The values of $\mathrm{C}_{\mathrm{PAH}}$, $\mathrm{C}_{\mathrm{In}}, \mathrm{C}_{\mathrm{Osm}}, \mathrm{TC}_{\mathrm{H}_{2} \mathrm{O}}$, and $\dot{V}$ in each rat were normalized by kidney weight (KW). Values from $\mathrm{U}_{1}$ to $\mathrm{U}_{4}$ periods were averaged. Mean arterial pressure (MAP) was determined at the mid-point of $\mathrm{U}_{1}$ to $\mathrm{U}_{4}$ periods and calculated from diastolic blood pressure (DBP) $+1 / 3$ pulse pressure (PP). The RVR was calculated using equation RVR $=\mathrm{MAP} / \mathrm{ERPF}$. The MAP and RVR during $\mathrm{U}_{1}$ to $\mathrm{U}_{4}$ periods were also averaged.

\section{Test of toxicity of GD flower extract in the sub-chronic protocol}

The animals in this group were orally administered with either vehicle, 50, 100, or $200 \mathrm{mg} / \mathrm{kg}$ BW GD flower extract daily for 2 weeks. One night before the $A B P$, renal, and excretory function study, the rat was deprived of food but still allowed to access the drinking water. On the day of the experiment, the rat was anesthetized with isoflurane supplied with oxygen. Before an infusion of renal clearance markers, a small amount of blood was collected from the carotid artery catheter for measuring a level of FBG using a digital glucometer (Accu-Check, Basel, Switzerland). Then, the renal and excretory function study was performed as previously described. At the end of the experiment, $5 \mathrm{ml}$ of blood was collected from the carotid artery and centrifuged at $3000 \mathrm{rpm}$ for $10 \mathrm{~min}$ for plasma collection, and then the plasma sample was kept at $-20^{\circ} \mathrm{C}$ until analysis for the levels of plasma lipid profiles composed of cholesterol, triglyceride, highdensity lipoprotein (HDL), and low-density lipoprotein (LDL) and liver enzyme levels including aspartate transaminase (AST), alanine transaminase (ALT), and alkaline phosphatase (ALP) using standard technique (Health Care Service Center, Faculty of Allied Health Science, Thammasat University, Pathum Thani, Thailand). Finally, the rat was perfused with $0.1 \mathrm{M}$ phosphate buffer solution, and liver tissue samples were fixed in $10 \%$ formalin for histological study by hematoxylin and eosin (H\&E) staining (Laboratory of Pathology, Faculty of Medicine, Thammasat University, Pathum Thani, Thailand).

\section{Statistics}

Data were presented as mean \pm standard error of the mean (SEM). Comparisons between the means values within group and among groups of acute and sub-chronic treatment were performed with oneway analysis of variance followed by Tukey post hoc test using GraphPad Prism 6 (San Diego, CA, USA). A $p$-value of less than 0.05 was considered a significant difference. 


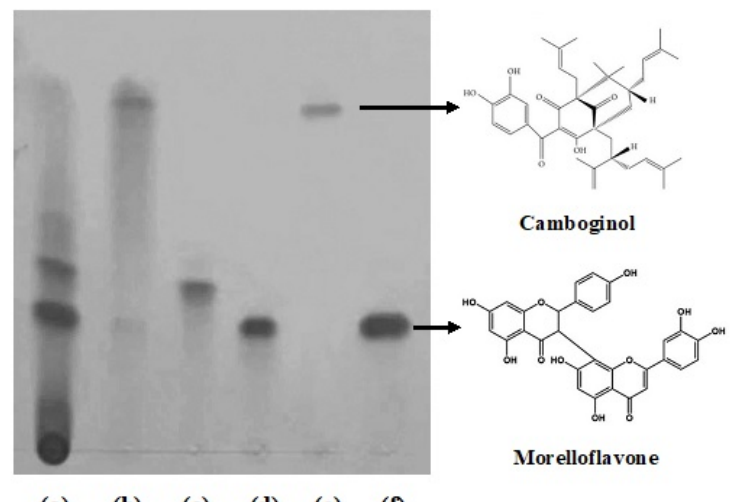

(a) (b) $\quad$ (c) $\quad$ (d) $\quad$ (e) $\quad$ (f)

Fig. 1 The chromatogram of the Garcinia dulcis flower extract: (a) hexane insoluble fraction, (b) fraction 1 , (c) fraction 2 , (d) fraction 3 , (e) camboginol $\left(\mathrm{C}_{38} \mathrm{H}_{50} \mathrm{O}_{6}\right.$, MW 602)), and (f) morelloflavone $\left(\mathrm{C}_{30} \mathrm{H}_{20} \mathrm{O}_{11}\right.$, MW 556).

\section{RESULTS}

\section{The chemical components of the GD flower extract}

The chromatogram showed that the hexane insoluble fraction is composed of camboginol and morelloflavone as shown in Fig. 1.

\section{Hypotensive effect of GD flower extract in acute and sub-chronic treatment groups}

Acute oral administration of GD flower extract at the doses of 100 and $200 \mathrm{mg} / \mathrm{kg}$ BW significantly decreased SBP, DBP, and MAP but did not change $\mathrm{PP}$ and HR in comparison to the vehicle as shown in Fig. 2a (SBP; GD-100: 89 \pm 3 , GD-200: $88 \pm 3$, and vehicle: $102 \pm 4 \mathrm{~mm} \mathrm{Hg}$, DBP; GD-100: $43 \pm 2$, GD-200: $44 \pm 2$, and vehicle: $57 \pm 4 \mathrm{~mm} \mathrm{Hg}$, MAP; GD-100: 59 \pm 2, GD-200: $54 \pm 3$, and vehicle: $72 \pm 4 \mathrm{~mm} \mathrm{Hg}, p<0.05)$. Acute treatment of $50 \mathrm{mg} / \mathrm{kg}$ BW GD flower extract did not affect the SBP, DBP, PP, MAP, and HR.

In sub-chronic treatment, oral administration 50 and $100 \mathrm{mg} / \mathrm{kg}$ BW GD flower extract significantly decreased SBP, DBP, and MAP in comparison to the vehicle as shown in Fig. 2b (SBP; GD-50: 94 \pm 2 , GD-100: $94 \pm 2$, and vehicle: $104 \pm 1 \mathrm{~mm}$ Hg, DBP; GD-50: $38 \pm 1$, GD-100: $37 \pm 4$, and vehicle: $48 \pm 2 \mathrm{~mm} \mathrm{Hg}$, MAP; GD-50: $56 \pm 0.5$, GD100: $56 \pm 3$, and vehicle: $67 \pm 1 \mathrm{~mm} \mathrm{Hg}, p<0.05$ ). Oral administration of $200 \mathrm{mg} / \mathrm{kg}$ BW GD flower extract significantly decreased SBP and PP but did not change DBP, MAP, and HR compared with vehicle (SBP; GD-200: $95 \pm 3$ and vehicle: $104 \pm 1$, PP; GD-
Table 1 Effect of acute and sub-chronic treatment of either vehicle or Garcinia dulcis flower extract at the doses of 50,100 , and $200 \mathrm{mg} / \mathrm{kg} \mathrm{BW}$ on heart rate (HR), hematocrit $(\mathrm{Hct})$, and plasma osmolarity $\left(\mathrm{P}_{\mathrm{Osm}}\right)$.

\begin{tabular}{|c|c|c|c|}
\hline Group & $\begin{array}{c}\mathrm{HR} \\
(\mathrm{BPM})\end{array}$ & $\begin{array}{l}\text { Hct } \\
(\%)\end{array}$ & $\begin{array}{c}\mathrm{P}_{\mathrm{Osm}} \\
\left(\mathrm{mOsm} / \mathrm{kg} \mathrm{H} \mathrm{H}_{2} \mathrm{O}\right)\end{array}$ \\
\hline \multicolumn{4}{|c|}{ Acute treatment } \\
\hline Vehicle & $402 \pm 12$ & $41.0 \pm 0.9$ & $291 \pm 2$ \\
\hline GD-50 & $426 \pm 6$ & $40.5 \pm 0.9$ & $289 \pm 2$ \\
\hline GD-100 & $414 \pm 9$ & $41.8 \pm 0.3$ & $289 \pm 1$ \\
\hline GD-200 & $422 \pm 15$ & $38.8 \pm 1.3$ & $292 \pm 1$ \\
\hline \multicolumn{4}{|c|}{ Sub-chronic treatment } \\
\hline Vehicle & $418 \pm 11$ & $38.9 \pm 0.7$ & $291 \pm 3$ \\
\hline GD-50 & $390 \pm 9$ & $43.3 \pm 1.1^{*}$ & $296 \pm 2^{*, * * *}$ \\
\hline GD-100 & $406 \pm 20$ & $41.4 \pm 0.9^{*}$ & $294 \pm 2^{*, * * *}$ \\
\hline GD-200 & $419 \pm 12$ & $47.0 \pm 3.2^{*, * *}$ & $300 \pm 2^{*, * * *}$ \\
\hline
\end{tabular}

Data were represented as mean \pm standard error of the mean (SEM). * $p<0.05$ in comparison with the vehicle within either acute or sub-chronic group and ** $p<0.05$ when compared between the acute and the sub-chronic treatment at the same dose of either vehicle or GD flower extract. BPM, beat per minute.

200: $42 \pm 4$ and vehicle: $56 \pm 2 \mathrm{~mm} \mathrm{Hg}, p<0.05)$.

\section{The diuretic effect of GD flower extract}

All doses of acute oral administration of GD flower extract significantly decreased RVR compared with the vehicle as shown in Fig. 3 (GD-50: $15 \pm 2$, GD-100: $13 \pm 3$, GD-200: $13 \pm 2$, and vehicle: $28 \pm 12 \mathrm{RU}, p<0.05)$. The extract significantly raised $\mathrm{C}_{\mathrm{PAH}}, \mathrm{C}_{\mathrm{In}}, \dot{\mathrm{V}}, \mathrm{C}_{\mathrm{Osm}}$, and $\mathrm{TC}_{\mathrm{H}_{2} \mathrm{O}}$ in comparison to vehicle ( $\mathrm{C}_{\mathrm{PAH}}$; GD-50: $4.92 \pm 0.96$, GD100: $4.96 \pm 0.63$, GD-200: $4.98 \pm 0.99$, and vehicle: $2.72 \pm 0.06 \mathrm{~mL} / \mathrm{min} / \mathrm{g} \mathrm{KW}, \mathrm{C}_{\text {In }}$; GD-50: $1.69 \pm 0.14$, GD-100: $1.74 \pm 0.15$, GD-200: $1.67 \pm 0.36$, and vehicle: $0.79 \pm 0.07 \mathrm{~mL} / \mathrm{min} / \mathrm{g} \mathrm{KW}, \dot{\mathrm{V}} ; \mathrm{GD}-50$ : $11.36 \pm 0.28$, GD-100: $11.65 \pm 0.32$, GD-200: $12.17 \pm 1.01$, and vehicle: $8.87 \pm 0.94 \mathrm{~mL} / \mathrm{min} / \mathrm{g}$ KW, $\mathrm{C}_{\text {Osm }}$; GD-50: $48 \pm 3$, GD-100: $53 \pm 3$, GD-200: $49 \pm 6$, and vehicle: $33 \pm 3 \mu \mathrm{L} / \mathrm{min} / \mathrm{g} \mathrm{KW}, \mathrm{TC}_{\mathrm{H}_{2} \mathrm{O}}$; GD-50: $34 \pm 3$, GD-100: $41 \pm 3$, GD-200: $37 \pm 6$, and vehicle: $24 \pm 3 \mu \mathrm{L} / \mathrm{min} / \mathrm{g} \mathrm{KW}, p<0.05)$. All doses of acute treatment of GD flower extract did not change $\mathrm{U}_{\mathrm{Osm}}$ and $\mathrm{P}_{\mathrm{Osm}}$.

The $\mathrm{C}_{\mathrm{PAH}}, \dot{\mathrm{V}}, \mathrm{C}_{\mathrm{Osm}}, \mathrm{TC}_{\mathrm{H}_{2} \mathrm{O}}$, and $\mathrm{U}_{\mathrm{Osm}}$ did not change after treatment of GD flower extract subchronically as shown in Fig. 4. However, the RVR significantly decreased in the $100 \mathrm{mg} / \mathrm{kg}$ BW GD treatment group but significantly increased in the $200 \mathrm{mg} / \mathrm{kg}$ BW GD treatment group in comparison to the vehicle (GD-100: 14.90 \pm 1.13 , GD- 

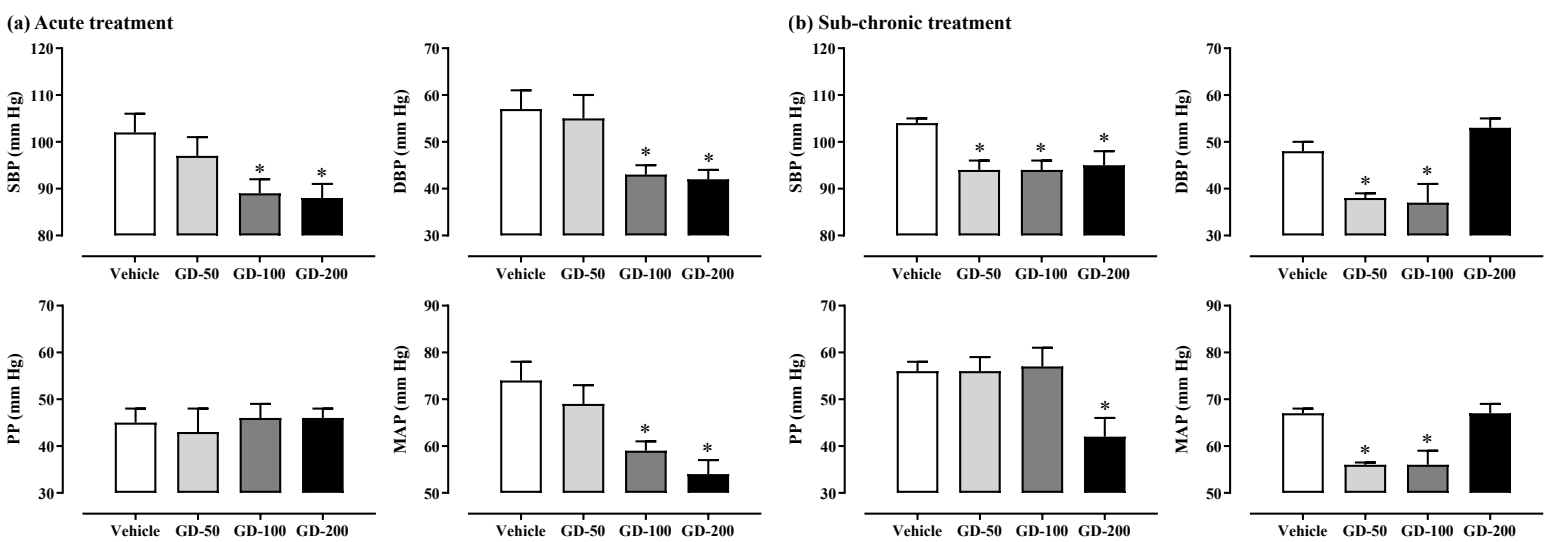

Fig. 2 The hypotensive effect of the Garcinia dulcis flower extract at the doses of 0 (vehicle), 50, 100, and $200 \mathrm{mg} / \mathrm{kg}$ BW: (a) acute and (b) sub-chronic treatment protocol. * $p<0.05$ in comparison to vehicle. SBP, systolic blood pressure; DBP, diastolic blood pressure; PP, pulse pressure; and MAP, mean arterial pressure.

a)

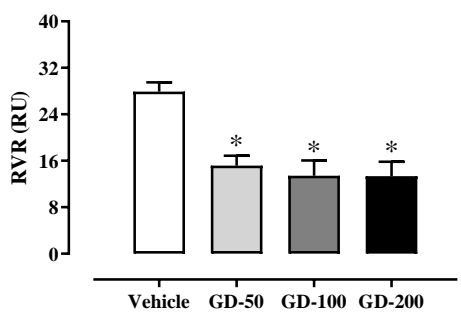

d)

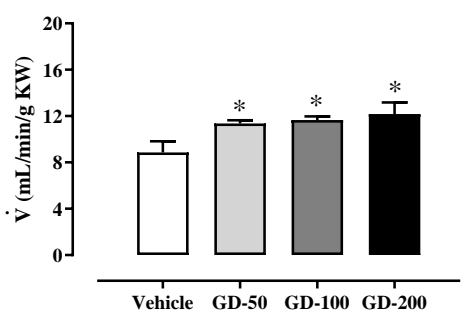

b)

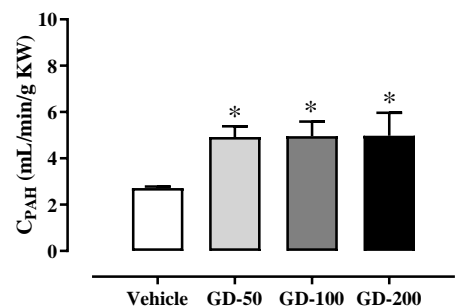

e)

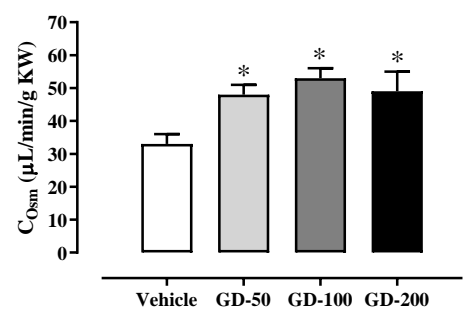

c)

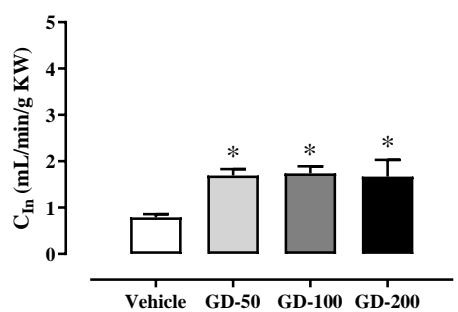

f)

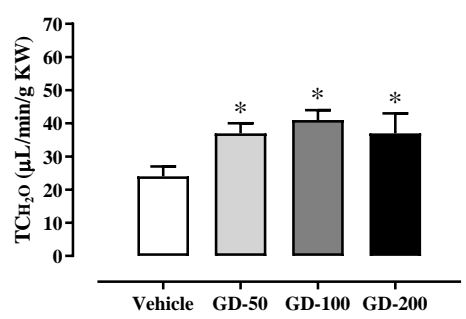

Fig. 3 The acute diuretic effect of the Garcinia dulcis flower extract at the doses of 0 (vehicle), 50, 100, and 200 mg/kg BW: a) renal vascular resistance (RVR), b) clearance of para-amino hippuric acid $\left(\mathrm{C}_{\mathrm{PAH}}\right)$, c) clearance of inulin $\left(\mathrm{C}_{\mathrm{In}}\right)$, d) urine flow rate $(\dot{\mathrm{V}})$, e) osmolar clearance $\left(\mathrm{C}_{\mathrm{Osm}}\right)$, and $\mathrm{f}$ ) negative free water clearance $\left(\mathrm{TC}_{\mathrm{H}_{2} \mathrm{O}}\right)$. $* p<0.05$ in comparison to vehicle. KW, kidney weight.

200: $25.26 \pm 1.52$, and vehicle: $18.73 \pm 1.15 \mathrm{RU}$, $p<0.05)$. It was also found that $\mathrm{C}_{\text {In }}$ significantly increased in the group of $200 \mathrm{mg} / \mathrm{kg}$ BW GD flower extract treatment in comparison to the vehicle (GD-200: $2.69 \pm 0.22$ and vehicle: $1.05 \pm 0.05$, $p<0.05)$. Moreover, it was found that treatment of GD flower extract significantly increased hematocrit (Hct) and $\mathrm{P}_{\mathrm{Osm}}$ in comparison to the vehicle as represented in Table 1 (Hct; GD-50: $43.3 \pm 1.1$, GD-100: 41.4 \pm 0.9 , GD-200: $47.0 \pm 3.2$, and vehicle: $38.9 \pm 0.7 \%, \mathrm{P}_{\text {Osm }}$; GD-50: $296 \pm 2$, GD-100: $294 \pm 2$, GD-200: $300 \pm 2$, and vehicle: $291 \pm 3 \mathrm{mOsm} / \mathrm{kg} \mathrm{H} \mathrm{O}, p<0.05$ ).

\section{BW, FBG, plasma lipid profile, liver enzymes, and histology of liver}

In the sub-chronic protocol, all doses of GD flower extract did not change the BW, FBG levels, the plasma levels of cholesterol, triglyceride, HDL, LDL, AST, ALT, and ALP in comparison to vehicle 
a)

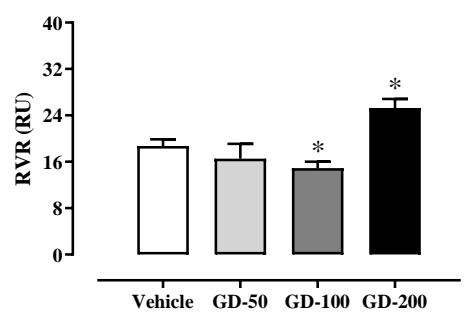

d)

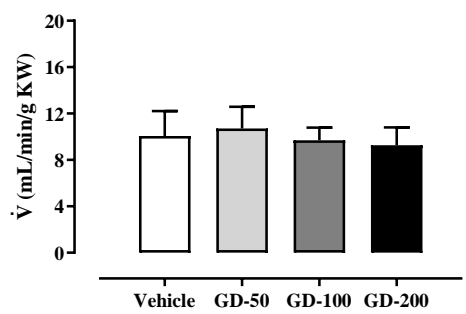

b)

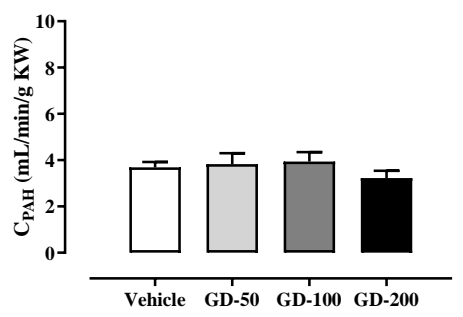

e)

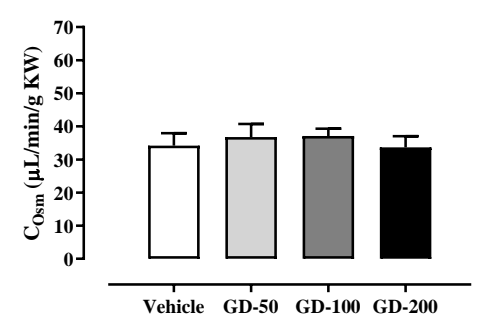

c)

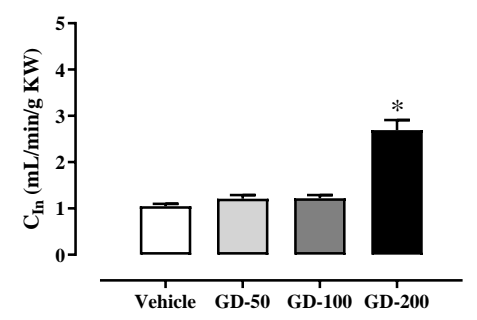

f)

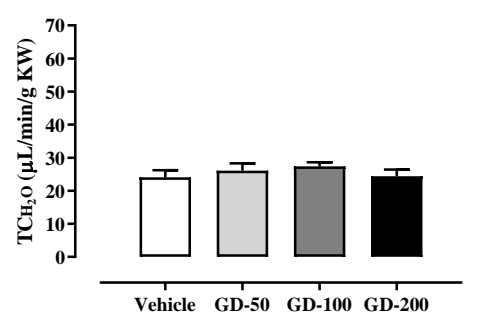

Fig. 4 Effect of sub-chronic treatment of the Garcinia dulcis flower extract at the doses of 0 (vehicle), 50, 100, and $200 \mathrm{mg} / \mathrm{kg}$ BW on renal excretory functions: a) renal vascular resistance (RVR), b) clearance of para-amino hippuric acid $\left(\mathrm{C}_{\mathrm{PAH}}\right)$, c) clearance of inulin $\left(\mathrm{C}_{\mathrm{In}}\right)$, d) urine flow rate $(\dot{\mathrm{V}})$, e) osmolar clearance $\left(\mathrm{C}_{\mathrm{Osm}}\right)$, and $\mathrm{f}$ ) negative free water clearance $\left(\mathrm{TC}_{\mathrm{H}_{2} \mathrm{O}}\right)$. ${ }^{*} p<0.05$ in comparison to vehicle. $\mathrm{KW}$, kidney weight.

(Table S1). The H\&E staining of liver tissues did not observe any pathology change (Fig. S1).

\section{DISCUSSION}

The TLC showed that the hexane insoluble fraction of the GD flower extract is composed of camboginol and morelloflavone (Fig. 1). Camboginol, also called garcinol, is a benzophenone which exerted a wide range of physiological activities including antioxidation, vasodilation, anti-inflammation, anti-cancer, anti-HIV, and anti-ulcer [10-12, 1623]. Another active compound in this fraction is morelloflavone biflavonoid comprising 2 flavones: apigenin and luteolin occurring in most Garcinia species [24]. The previous study reported that morelloflavone inhibits vascular smooth muscle cell migration, invasion, and lamellipodium formation through activation of multiple migration-related kinases including focal adhesion kinase, Src, extracellular signal-regulated kinase, and RhoA [25]. Oral morelloflavone therapy for 8 months significantly reduced the atherosclerotic areas of the mouse aortae [26]. The possible mechanism of those actions of camboginol and morelloflavone may be related to its antioxidant property.

The findings showed that the hypotensive effect of GD flower extract can be observed at the doses of
100 and $200 \mathrm{mg} / \mathrm{kg} \mathrm{BW}$ in the acute treatment and 50 and $100 \mathrm{mg} / \mathrm{kg} \mathrm{BW}$ in the sub-chronic treatment (Fig. 2). It was also found that the RVR decreased in all groups of acute treatment and the group of $100 \mathrm{mg} / \mathrm{kg}$ BW in the sub-chronic treatment (Fig. 3a and Fig. 4a). The decreased RVR in those groups was due to a decreased MAP with an increased ERPF since the RVR was calculated using the equation; RVR $=$ MAP/ERPF. Our previous studies found that both camboginol and morelloflavone induced vasorelaxation of the isolated thoracic aorta from either normotensive or hypertensive rat, and its mechanism of action involved endothelial NO-dependent signaling pathway $[10,11,13]$. The data suggested that the possible mechanism of hypotensive action may be due to vascular relaxation and reduction of the vascular resistance which involved endothelial NO-dependent pathway.

The hypotensive effect was absent in the group of acute $50 \mathrm{mg} / \mathrm{kg}$ BW treatment which may be due to less concentration of the GD flower extract (Fig. 2a). Interestingly, the DBP in the sub-chronic treatment groups at the doses of 50 and $100 \mathrm{mg} / \mathrm{kg}$ BW were greatly decreased, thus reflecting the strong vasorelaxation (Fig. 2b). While the DBP and MAP turned to the basal level, the SBP was still significantly lower than the control group in the sub- 
chronic treatment of $200 \mathrm{mg} / \mathrm{kg}$ BW. It was also found that the RVR and the $\mathrm{C}_{\text {In }}$ (as GFR) were significantly higher than the other groups because (1) the MAP turned to a normal level while the ERPF was slightly lower than the control and (2) the increased GFR suggested the vasoconstriction of the efferent arteriole. The absence of the hypotensive effect of the GD flower extract at the high dose may be due to the compensatory mechanisms of the body including baroreceptor reflex to increase sympathetic activity and the RAAS to increase angiotensin II level and then increased basal vascular tone [27].

The diuretic effect of GD flower extract was observed in the acute treatment of the GD flower extract (Fig. 3). The $\mathrm{C}_{\mathrm{PAH}}, \mathrm{C}_{\mathrm{In}}, \dot{\mathrm{V}}, \mathrm{C}_{\mathrm{Osm}}$, and $\mathrm{TC}_{\mathrm{H}_{2} \mathrm{O}}$ were significantly increased in comparison to the vehicle at all doses of GD flower extract. The findings corresponded with our previous studies which found that intravenous infusion of either camboginol or morelloflavone exerted diuretic action in both normotensive and hypertensive rats $[10,12]$. The mechanism of diuretic action may involve both glomerular and tubular functions. The GD flower extract relaxed the afferent arteriole and induced an increase of blood flow ( $\mathrm{C}_{\mathrm{PAH}}$ ) leading to an increase of intravenous hydrostatic pressure in the glomerulus, resulting in increased $\mathrm{GFR}\left(\mathrm{C}_{\text {In }}\right), \dot{\mathrm{V}}$, and urinary electrolyte excretion $\left(\mathrm{C}_{\mathrm{Osm}}\right)$. The water reabsorption $\left(\mathrm{TC}_{\mathrm{H}_{2} \mathrm{O}}\right)$ was significantly increased in the GD extract treatment groups which may be due to the action of anti-diuretic hormone (ADH) in response to hypotension and hypovolemia [28].

The diuresis of the GD flower extract was not observed in the sub-chronic treatment groups (Fig. 4). The water contraction was observed in those subchronic treated groups since the level of hematocrit and $\mathrm{P}_{\mathrm{Osm}}$ were significantly increased compared to vehicle control (Table 1). The mechanism of the water retraction may be because of the inhibitory effect of the extract on the thirst center. The extract may diminish action of ADH on the renal distal and collecting duct or diminish ADH synthesis and release itself. Physiologically, the compensatory responses to the water contraction include increased vascular tone by activation of the sympathetic nervous system and secretion of angiotensin II which induced vasoconstriction of both afferent and efferent arterioles. Moreover, the plasma levels of $\mathrm{ADH}$ and aldosterone were also increased in response to water contraction, and increasing of $\mathrm{P}_{\mathrm{Osm}}$ resulted in increased water and sodium reabsorption at late distal tubule and collecting duct and finally decreased the urine output [27].

Oral administration of GD flower extract for 2 weeks did not change the BW, FBG levels, and the plasma levels of cholesterol, triglyceride, HDL, and LDL. These findings corresponded with the previous study which reported that oral morelloflavone therapy for 8 months did not change the plasma lipid profiles in Ldlr-/-Apobec1-/-mice [26]. Moreover, sub-chronic treatment of GD flower extract did not change the levels of AST, ALT, and ALP in comparison to the vehicle and did not cause the histological change of the liver suggesting oral administration of flower GD extract was non-toxic (Table S1 and Fig. S1).

It is concluded that acute oral administration of GD flower extract possessed hypotensive and diuretic effects. Sub-chronic treatment of GD flower extract showed a hypotensive effect and the absence of liver toxicity. The hypotensive and diuretic action of GD flower extract may relate to its antioxidant activity. The application of GD flower extract as an antihypertensive agent should be further pharmacologically studied in the hypertensive model.

\section{Appendix A. Supplementary data}

Supplementary data associated with this article can be found at http://dx.doi.org/10.2306/ scienceasia1513-1874.2020.095.

Acknowledgements: This research was financially supported by the Thammasat University Research Fund under the TU Research Scholar, Contract No. 2/41/2561. It also was supported by the Laboratory of Pathology, Faculty of Medicine, Thammasat University, Pathum Thani, Thailand for histological study.

\section{REFERENCES}

1. Julius S, Nesbitt S (1996) Sympathetic overactivity in hypertension. A moving target. Am J Hypertens 9 , 113S-120S.

2. Manrique C, Lastra G, Gardner M, Sowers JR (2009) The renin-angiotensin-aldosterone system in hypertension: roles of insulin resistance and oxidative stress. Med Clin North Am 93, 569-582.

3. Blaustein MP, Zhang J, Chen L, Hamilton BP (2006) How does salt retention raise blood pressure? Am J Physiol Regul Integr Comp Physiol 290, R514-R523.

4. Brandes RP (2014) Endothelial dysfunction and hypertension. Hypertension 64, 924-928.

5. Yan W, Liu K, Zheng Y, Cao J, Zhang A, Wei G, Zeng Q (2018) Antihypertensive effect of a Chinese herbal formula (Salvia miltiorrhiza compound recipe) in hypertensive rats induced by high-fructose, highsalt,and high-fat diet. ScienceAsia 44, 187-196. 
6. Deachathai S, Mahabusarakam W, Phongpaichit S, Taylor WC (2005) Phenolic compounds from the fruit of Garcinia dulcis. Phytochemistry 66, 2368-2375.

7. Dechathai S, Mahabussarakam W, Phongpaichit S, Taylor WC, Zhang YJ, Yang CR (2006) Phenolic compounds from the flowers of Garcinia dulcis. Phytochemistry 67, 464-469.

8. Deachathai S, Phongpaichit S, Mahabusarakam W (2008) Phenolic compounds from the seeds of Garcinia dulcis. Nat Prod Res 22, 1327-1332.

9. Mahabusarakam W, Mecawun P, Phongpaichit S (2016) Xanthones from the green branch of Garcinia dulcis. Nat Prod Res 30, 2323-2328.

10. Thongsepee N, Mahabusarakam W, Hiranyachattada S (2017) Diuretic and hypotensive effect of morelloflavone from Garcinia dulcis in two-kidneysone-clip (2K1C) hypertensive rat. Sains Malaysiana 46, 1479-1490.

11. Thongsepee N, Mahabusarakam W, Hiranyachattada S (2018) Vasorelaxant mechanisms of camboginol from Garcinia dulcis in normotensive and 2-kidneys1-clip hypertensive rat. Songklanakarin J Sci Technol 40, 1248-1258.

12. Thongsepee N, Mahabusarakam W, Hiranyachattada S (2017) Diuretic effect of camboginol from Garcinia dulcis in 2-kidneys-1-clip hypertensive rat. In: Proc of the Burapha University International Conference 2017, Chonburi, Thailand, pp 613-622.

13. Lamai J, Mahabusarakam W, Ratithammatorn T, Hiranyachattada S (2013) Effects of morelloflavone from Garcinia dulcis on vasorelaxation of isolated rat thoracic aorta. J Physiol Biomed Sci 26, 13-17.

14. Smith HW, Finkelstein N, Aliminoso L, Crawford B, Graber M (1945) The renal clearances of substituted hippuric and derivatives and other aromatic acids in dogs and man. $J$ Clin Invest 24, 388-404.

15. Davidson WD, Sackner MA (1963) Simplification of anthrone method of the determination of inulin in clearance studies. J Lab Clin Med 62, 351-356.

16. Yamaguchi F, Ariga T, Yoshimura Y, Nakazawa H (2000) Antioxidative and anti-glycation activity of garcinol from Garcinia indica fruit rind. J Agr Food Chem 48, 180-185.

17. Yamaguchi F, Saito M, Ariga T, Yoshimura Y, Nakazawa H (2000) Free radical scavenging activity and antiulcer activity of garcinol from Garcinia indica fruit rind. J Agr Food Chem 48, 2320-2325.

18. Liao CH, Sang S, Liang YC, Ho CT, Lin JK (2004)
Suppression of inducible nitric oxide synthase and cyclooxygenase-2 in downregulating nuclear factorkappa B pathway by Garcinol. Mol Carcinog 41, 140-149.

19. Hong J, Sang S, Park HJ, Park HJ, Kwon SJ, Suh N, Yang CS (2006) Modulation of arachidonic acid metabolism and nitric oxide synthesis by garcinol and its derivatives. Carcinogenesis 27, 278-286.

20. Kim SY, Kim TB, Moon KA, Kim TJ, Shin D, Cho YS, Lee KY (2008) Regulation of pro-inflammatory responses by lipoxygenases via intracellular reactive oxygen species in vitro and in vivo. Exp Mol Med 40, 461-476.

21. Tanaka T, Kohno H, Shimada R, Kagami S, Yamaguchi F, Kataoka S, Ohigashi H (2000) Prevention of colonic aberrant crypt foci by dietary feeding of garcinol in male F344 rats. Carcinogenesis 21, 1183-1189.

22. Balasubramanyam K, Altaf M, Varier RA, Swaminathan V, Ravindran A, Sadhale PP, Kundu TK (2004) Polyisoprenylated benzophenone, garcinol, a natural histone acetyltransferase inhibitor, represses chromatin transcription and alters global gene expression. J Bio Chem 279, 33716-33726.

23. Das D, Bandyopadhyay D, Bhattacharjee M, Banerjee RK (1997). Hydroxyl radical is the major causative factor in stress-induced gastric ulceration. Free Radical Bio Med 23, 8-18.

24. Verbeek R, Plomp AC, van Tol EA, van Noort JM (2004) The flavones luteolin and apigenin inhibit in vitro antigen-specific proliferation and interferongamma production by murine and human autoimmune T cells. Biochem Pharmacol 68, 621-629.

25. Pinkaew D, Cho SG, Hui DY, Wiktorowicz JE, Hutadilok-Towatana N, Mahabusarakam W, Tonganunt M, Stafford LJ, et al (2009) Morelloflavone blocks injury-induced neointimal formation by inhibiting vascular smooth muscle cell migration. Biochim Biophys Acta 1790, 31-39.

26. Pinkaew D, Hutadilok-Towatana N, Teng BB, Mahabusarakam W, Fujise K (2012) Morelloflavone, a biflavonoid inhibitor of migration-related kinases, ameliorates atherosclerosis in mice. Am $J$ Physiol Heart Circ Physiol 302, H451-H458.

27. Guyton AC, Hall JE (2006) Textbook of Medical Physiology, Philadelphia, Elseveir Inc., Pennsylvania, USA.

28. Boone M, Deen PM (2008) Physiology and pathophysiology of the vasopressin-regulated renal water reabsorption. Pflugers Arch 456, 1005-1024. 


\section{Appendix A. Supplementary data}

Table S1 Effect of Sub-chronic treatment of either vehicle or Garcinia dulcis flower extract at the doses of 50, 100, and $200 \mathrm{mg} / \mathrm{kg}$ BW on body weight change, fasting blood glucose, plasma lipid profile, and liver enzymes.

\begin{tabular}{|c|c|c|c|c|c|}
\hline Parameter & Vehicle $(n=6)$ & GD-50 $(n=6)$ & GD-100 $(n=6)$ & GD-200 $(n=6)$ & $p$ \\
\hline BW at day $0, \mathrm{~g}$ & $284 \pm 14$ & $323 \pm 10$ & $310 \pm 10$ & $318 \pm 7$ & ns \\
\hline$\Delta \mathrm{BW}$ at day $14, \mathrm{~g}$ & $+47 \pm 5$ & $+50 \pm 10$ & $+55 \pm 8$ & $+53 \pm 3$ & ns \\
\hline $\mathrm{FBG}, \mathrm{mg} / \mathrm{dL}$ & $126 \pm 13$ & $118 \pm 15$ & $124 \pm 10$ & $124 \pm 18$ & ns \\
\hline Cholesterol, mg/dL & $52 \pm 4$ & $51 \pm 7$ & $53 \pm 2$ & $49 \pm 4$ & ns \\
\hline Triglyceride, mg/dL & $54 \pm 8$ & $48 \pm 4$ & $72 \pm 9$ & $65 \pm 13$ & ns \\
\hline $\mathrm{HDL}, \mathrm{mg} / \mathrm{dL}$ & $33 \pm 3$ & $32 \pm 2$ & $34 \pm 1$ & $29 \pm 2$ & ns \\
\hline $\mathrm{LDL}, \mathrm{mg} / \mathrm{dL}$ & $5 \pm 1$ & $3 \pm 1$ & $5 \pm 1$ & $4 \pm 1$ & ns \\
\hline AST, U/L & $57 \pm 2$ & $49 \pm 3$ & $53 \pm 3$ & $64 \pm 3$ & ns \\
\hline ALT, U/L & $18 \pm 2$ & $18 \pm 3$ & $16 \pm 4$ & $14 \pm 1$ & ns \\
\hline ALP, U/L & $64 \pm 5$ & $55 \pm 7$ & $61 \pm 8$ & $52 \pm 5$ & ns \\
\hline
\end{tabular}

Data were represented as mean \pm standard error of the mean (SEM). $\Delta$ BW, body weight change (+increase); FBG, fasting blood glucose; HDL, high-density lipoprotein; LDL, low-density lipoprotein; AST, aspartate transaminase; ALT, alanine transaminase; ALP, alkaline phosphatase; and ns, non-significant when compared with vehicle.

\section{a) Vehicle}

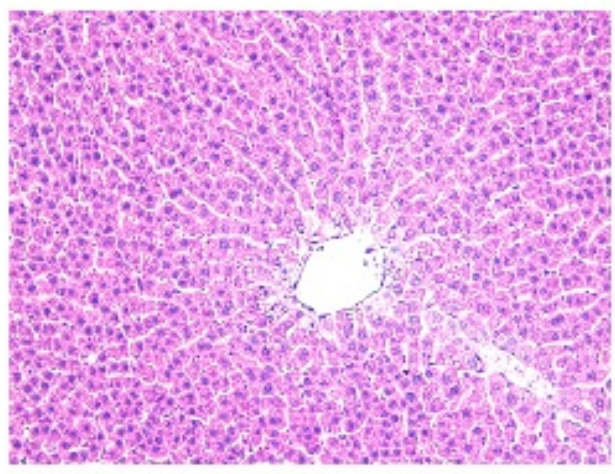

c) GD $100 \mathrm{mg} / \mathrm{kg}$

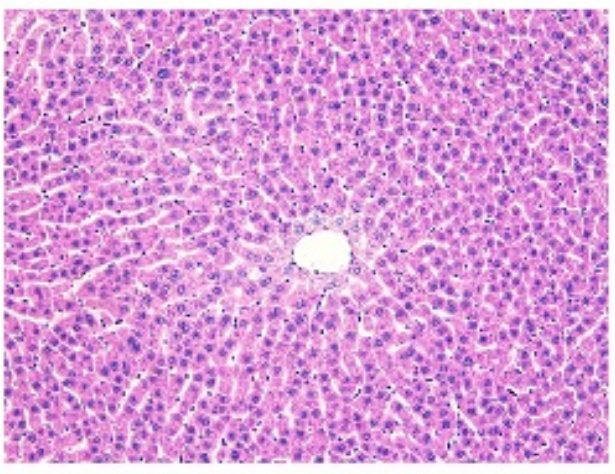

b) GD $50 \mathrm{mg} / \mathrm{kg}$

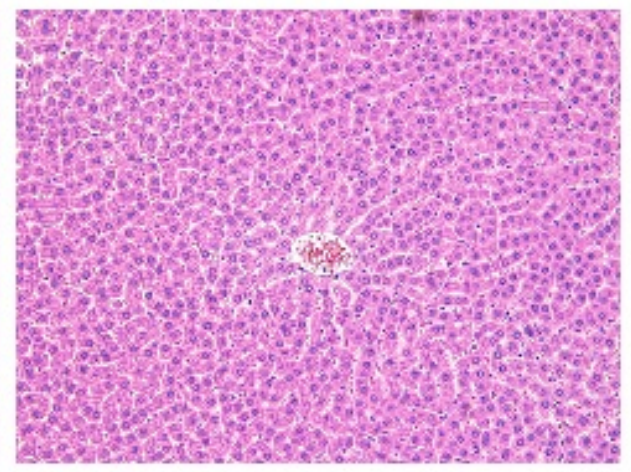

d) GD $200 \mathrm{mg} / \mathrm{kg}$

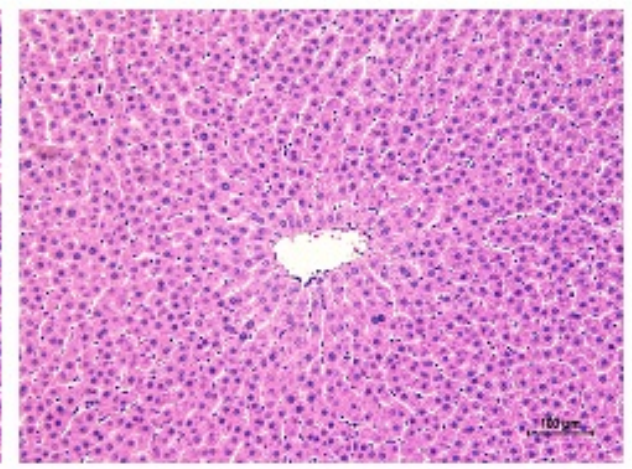

Fig. S1 Histological examination (hematoxylin and eosin staining) of sub-chronic treatment of either a) vehicle or Garcinia dulcis flower extract at the dose of b) 50, c) 100, and d) $200 \mathrm{mg} / \mathrm{kg}$ BW. Magnification power $=200 \times$. 